\title{
Strength Evaluation of Sustainable Concrete with Partial Replacement of Cement by Combination of Banana Leaf Powder and Cattle Bone Powder
}

\author{
Ramya M, Mercy Shanthi R, Suji D
}

\begin{abstract}
In addition to cost, depletion of lime stone deposits, high energy usage and emission of carbon dioxide (CO2) are disadvantages associated with cement production. Day to day increase in cement demand leads to increase in cement production and there by increases carbon dioxide (CO2) emissions, which significantly increases global warming. An attempt is made to reduce $\mathrm{CO} 2$ emission by reducing the cement consumption in construction industry there by creating an environmental friendly sustainable green concrete for modern construction world. Supplementary Cementitious Material (SCM) can replace some quantity of cement in making concrete and mortar, thereby reduces the cement consumption by construction industry. Already ash form of cementitious materials derived from groundnut shell, bamboo leaves, rice husk, periwinkle shell are used as SCM's to reduce the cement content with increase in strength parameters. But, when SCM's are used in ash form, loss of energy and emission of $\mathrm{CO} 2$ creates negative impact. An alternate method of using waste materials as SCM in powder form increases the strength parameters of concrete. Combination of waste Banana Leaf Powder (BLP) and Cattle Bone Powder $(C B P)$, when used as $S C M$ increases the strength of concrete and mortar. Banana leaf Powder serves as an alternate binding material whereas Cattle Bone Powder, rich in calcium content improves the binding property of cementitious substances with aggregates thereby improves the bond strength between cement phase and aggregate phase.
\end{abstract}

Index Terms- Sustainability, Supplementary Cementitious Material, Banana Leaf Powder, Cattle Bone Powder.

\section{INTRODUCTION}

Million tons of waste banana leaves and cattle bones are disposed as landfills, which is unsustainable to the environment. Combined use of powdered banana leaf and powdered cattle bones in concrete as partial replacement of cement could be an appreciating initiative to develop a sustainable green concrete. Global cement demand is increasing significantly, leading to increase in $\mathrm{CO} 2$ emission, which is harmful to the environment. This initiative reduces overall consumption of cement, thereby reduces $\mathrm{CO} 2$ emission. [1]

\section{SUSTAINABLE GREEN CONCRETE}

Green Concrete is an ecofriendly concrete in which waste products generated by the society are used in concrete thereby reduces the environmental impact. One of the major

Revised Manuscript Received on April 12, 2019.

Ramya M,Department of Civil Engineering, Karunya University, Coimbatore (Tamilnadu), India.

Mercy Shanthi R, Department of Civil Engineering, Karunya University, Coimbatore (Tamilnadu), India.

Suji D, Department of Civil Engineering, P.S.G College of Technology, Coimbatore (Tamilnadu), India. causes for global warming is emission of $\mathrm{CO} 2$ from various sources. So it is important to focus on all sources of $\mathrm{CO} 2$ emissions in environment and one such source is from cement industry. Till date suitable measures are not available to eliminate $\mathrm{CO} 2$ emission from cement industry. Hence an attempt is made to reduce $\mathrm{CO} 2$ emission from cement industry through concrete. Though we are focusing mainly on $\mathrm{CO} 2$ emission, it is equally important to focus on performance of concrete in order to increase its operational sustainability benefits. Reducing the cement consumption by partial replacement of cement with waste materials is an effective way to increase the performance of concrete and makes the concrete more sustainable with low $\mathrm{CO} 2$ emissions. [2]

In addition, there are some barriers in using waste materials in concrete. Major barrier in using waste materials in concrete is lack of quantitative data. Also understanding between academic concept of green concrete and industrial requirements on green concrete is also lacking. These barriers are to be removed in order to derive potential benefits of sustainable green concrete. [3] [4]

\section{SUPPLEMENTARY CEMENTITIOUS MATERIAL (SCM)}

Ancient Greeks are the initiators of supplementary cementitious material. They created a strong hydraulic lime mortar using volcanic ash as supplementary cementitious material. SCM's are able to replace some quantity of Portland cement and still the cementitious property is exhibited well. Based on the type of reaction, SCM's are divided into two major categories: pozzolanic or hydraulic. In India, fly ash is used as major supplementary cementitious material. Now a day, egg shell, quartz sand, saw dust ash, leaf ash, rice husk ash and agricultural byproducts are also used as SCM's. [5]

\section{ALTERNATE BINDING MATERIAL}

Lime stone is the major raw material of cement. High demand of cement and insufficient availability of raw materials increases the cement price day by day. High cost of cement increases the requirement to find out cost effective alternative binding materials to maintain the binding material quantity requirements of construction industry. [6]

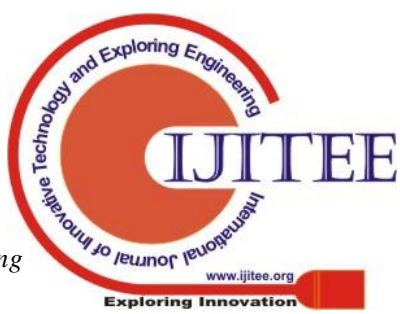




\section{Strength Evaluation Of Sustainable Concrete With Partial Replacement Of Cement By Combination Of Banana Leaf Powder And Cattle Bone Powder}

In addition to cost, high cement production increases the emission of $\mathrm{CO} 2$, which leads to global warming. Also, depletion of lime stone deposits at faster rate and demand of other raw materials are disadvantages in cement production. [7]. Production of Portland cement rate is lesser than that of demand rate and hence the cement price is increasing continuously. Construction industry is not able to meet requirements of economical binding material [8]. As an alternative many waste products with binding property are blended with cement to meet the industrial requirement. [9]

Major advantage of using alternative binding materials from waste materials is conservation of natural resources deposits. Also, it eliminates the problems associated with waste material disposal [10]. Hence Banana Leaf wastes and Cattle Bone wastes are selected as alternate binding material. Banana Leaf is a waste material and is available in plenty of quantity. Though banana leaf is an organic decomposable material, due to its time of decomposition and volume of waste from day to day activities, its disposal is critical. Similarly, Cattle bones are also dumped in large quantities in disposal yards and creates bad odor thereby creates air pollution and diseases. Hence it is necessary to dispose the above said waste in short span of time through an efficient way. Banana leaf wastes are collected and dried. After drying, banana leaves are crushed through commonly available milling machine to powder form. This BLP is rich in micro and macro scale fibers. When BLP is used to partially replace cement in concrete, it exhibits binding property. Also the fibres in BLP improve the bond strength of cement and aggregate phases.

\section{METHODOLOGY}

\section{Selection of Materials for Concrete}

Ordinary Portland cement (OPC), 53 Grade is used for concrete. Its specific gravity is 3.15. Fine Aggregate is selected from locally available normal sand confirming to grading zone II and specific gravity 2.6. Coarse aggregate is selected from locally available crushed blue granite stones of nominal size $20 \mathrm{~mm}$ and specific gravity is 2.75 . Combination of banana leaf powder (BLP) and cattle bone powder (CBP) are used as supplementary cementitious material for partial replacement of cement.

\section{Scanning Electron Microscope Observation}

Banana Leaf powder is fibrous in nature and the fiber particles are distributed in uniform cluster fashion. Texture of particles is flaky and elongated. Surface area of individual particles is more than that of individual particles of cement. Dried and powdered plasma in the BLP acts as distribution medium for the fibers, which is expected to improve bond strength of aggregate and cement phase when used in concrete.

\section{Mix Proportion}

M25 grade of concrete is proposed for this work. Mix ratio of 1:1:2 (cement: fine aggregate: coarse aggregate) is adopted for making concrete. Water cement ratio of 0.5 is adopted at medium level of exposure. Potable water with $\mathrm{pH}$ value 7.4 is used for concreting works. Cement quantity is taken with reference to weigh batching. 20\%, 30\% and $40 \%$ of weight of cement is replaced with (BLP+CBP).

\section{Casting of Concrete Specimens}

$($ Cement + BLP + CBP $)$ are mixed in a dry pan and the mixture is then added with measured sand quantity in dry state. Coarse aggregates are wetted with water and they dry mixture (Cement + BLP + CBP + Sand) is added with coarse aggregate. Water is slowly added and the concrete is mixed until it reaches the casting consistency. Medium level degree of supervision is required for this mixing work. The concrete mixture is tough to workable. Boscocem 425, a rubber later emulsion is added as admixture to improve the workability of BLP used concrete.

\section{TEST RESULT OF CONCRETE}

\section{Failure at Cracking and Collapse State}

Failure of the cube specimens under compression loading is analyzed at cracking state and collapse state. The compressive strength values are compared with that of the control specimen. It is observed that control specimen develops thick vertical cracks at the time of failure and also spalling of concrete occurs at cracking state itself. Some detachment of coarse aggregate from the cement matrix is also noted. But in BLP used concrete, there is no spalling of concrete at cracking state. Only inclined thin cracks are developed and no signs of vertical cracks in the failed specimen. Spalling of concrete occurs in the collapse state only. Also there is no detachment of bond between coarse aggregate and cement matrix even at collapse state. Test specimen at cracking state and collapse state are shown in Fig. 1 and Fig. 2 respectively.

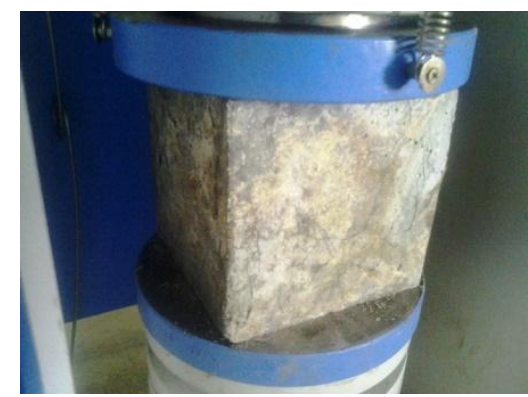

Fig.1 Test Specimen at Cracking

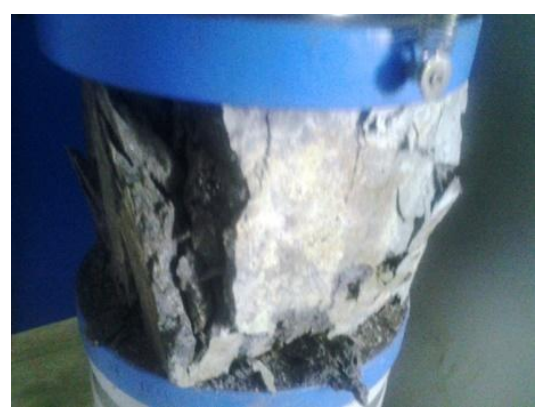

Fig.2 Test Specimen at Collapse

\section{Compressive Strength}

Hardened concrete specimens are tested at various ageing on 3, 7, 14 and 28 days of water curing period. Compressive strength values are recorded and the values are given in Table. 1 
Table.1 Compressive Strength of BLP+CBPused concrete cubes (with admixture)

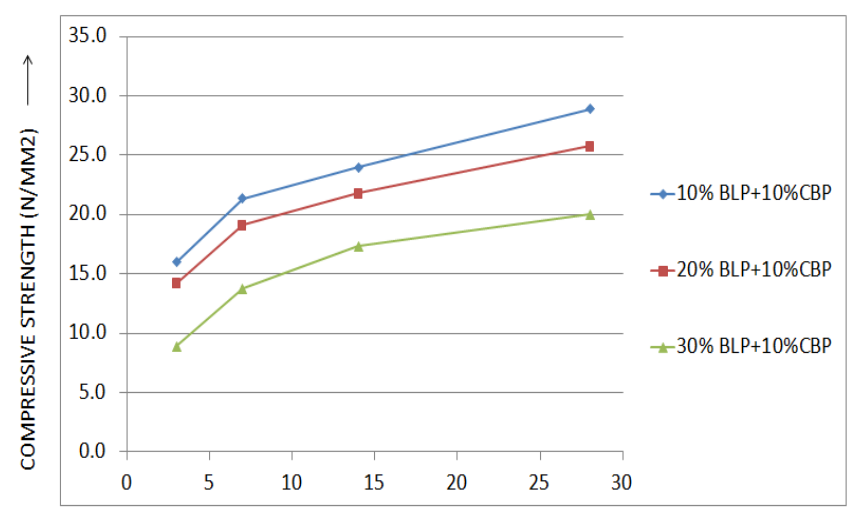

AGEING (IN DAYS) $\longrightarrow$

\begin{tabular}{|c|c|c|c|c|c|}
\hline $\begin{array}{c}\text { Grade of } \\
\text { Concrete }\end{array}$ & $\%$ BLP & $\%$ CBP & Admixture & Age (days) & $\begin{array}{c}\text { Compressive } \\
\text { Strength } \\
\text { (N/mm } \mathbf{~}^{2}\end{array}$ \\
\hline M25 & $10 \%$ & $10 \%$ & Yes & 3 & 16.0 \\
\hline M25 & $10 \%$ & $10 \%$ & Yes & 7 & 21.3 \\
\hline M25 & $10 \%$ & $10 \%$ & Yes & 14 & 24.0 \\
\hline M25 & $10 \%$ & $10 \%$ & Yes & 28 & 28.9 \\
\hline M25 & $20 \%$ & $10 \%$ & Yes & 3 & 14.2 \\
\hline M25 & $20 \%$ & $10 \%$ & Yes & 7 & 19.1 \\
\hline M25 & $20 \%$ & $10 \%$ & Yes & 14 & 21.8 \\
\hline M25 & $20 \%$ & $10 \%$ & Yes & 28 & 25.8 \\
\hline M25 & $30 \%$ & $10 \%$ & Yes & 3 & 8.9 \\
\hline M25 & $30 \%$ & $10 \%$ & Yes & 7 & 13.8 \\
\hline M25 & $30 \%$ & $10 \%$ & Yes & 14 & 17.3 \\
\hline M25 & $30 \%$ & $10 \%$ & Yes & 28 & 20.0 \\
\hline
\end{tabular}

Graph.1 strength of BLP+CBP used concrete cubes

\section{CONCLUSION}

Partial replacement of cement (up to 30\%) with supplementary cementitious material made with waste banana leaf powder and cattle bone powder increases the compressive strength of concrete at 28 days. BLP used concrete takes 14 days to develop the target mean strength and after 14 days, the strength development is more than that of the control specimen. BLP exhibits pozzolonic property and it is also taking part in hydration process. Cracking in BLP used concrete is lesser than control specimen.

Concrete specimens are tested for organic growth at an age of 90 days, 180 days and 360 days and there is no organic growth observed. Also chemical components of BLP shows the presence of reactive components, which are responsible for its pozzolonic behavior.

\section{ACKNOWLEDGMENT}

The authors like to acknowledge and thank the Management of Karunya University, Coimbatore for the support and facilities provided to pursue this study.

\section{REFERENCES}

1. Emerging Energy-efficiency and $\mathrm{CO}_{2}$ Emission-reduction Technologies for Cement and Concrete Production, Ali Hasanbeigi, Lynn Price, Elina Lin, China Energy Group,
Energy Analysis and Environmental Impacts Department Environmental Energy Technologies Division Lawrence Berkeley National Laboratory

2. An Investigation of Current Status of "Green" Concrete in the Construction Industry, Ruoyu Jin and Qian Chen, 49th ASC Annual International Conference Proceedings.

3. Trends and developments in green cement and concrete technology, Mohammed S. Imbabi, Collette Carrigan, Sean McKenna, International Journal of Sustainable Built Environment (2013).

4. Concrete and Sustainable Development, VesaPenttala, American Concrete Institute (ACI) Materials Journal, V. 94, No. 5, September-October 1997.

5. A review of partial replacement of cement with some agro wastes, manassehjoel, nigerian journal of technology, vol. 29 no 2 , june 2010.

6. Stability of groundnut shell ash (GSA)/ordinary portland cement $(O P C)$ concrete in Nigeria, T.C. Nwofor and S. Sule, Pelagia Research Library Advances in Applied Science Research, 2012, 3 (4):2283-2287

7. Strength of Binary Blended Cement Composites Containing Pawpaw Leaf Ash, L. O. Ettu, J. C. Ezeh, and M. S. W. Mbajiorgu, International Journal of Advancements in Research \& Technology, Volume 2, Issue5, May-2013 ISSN 2278-7763

8. Experimental Study on Concrete with Bamboo Leaf Ash, P. Asha, A. Salman, R.ArunKumar,International Journal of Engineering and Advanced Technology (IJEAT) ISSN: 2249 - 8958, Volume-3 Issue-6, August 2014

9. Comparative evaluation of concrete properties with varying proportions of periwinkle shell and bamboo leaf ashes replacing cement, Umoh, a.a. and femi, o.o., ethiopian journal of environmental studies and management vol. 6 no.5 2013.

10. Banana leaves ashes as pozzolan for concrete and mortar of Portland Cement, Rodrigo C. Kanning, Kleber F. Portella, Mariana O.G.P. Bragança, Marcelle M. Bonato, Jeannette C.M. dos Santos, Construction and Building Materials 54 (2014) 460-465

11. Machine crushed animal bones as partial replacement of coarse aggregates in lightweight concrete, Javed Ahmad Bhat, Reyaz Ahmad Qasab and A. R. Dar, Asian Research Publishing Network (ARPN) Journal of Engineering and Applied Sciences, VOL. 7, NO. 9, SEPTEMBER 2012, ISSN 1819-6608

12. Improvement of black cotton soil with cattle bone powder Iorliam, A. Y., Obam, S. O. and Owinizi, S. A., American journal of scientific and industrial research (C) 2012, Science $\mathrm{Hu} \beta$, http://www.scihub.org/AJSIR ISSN:2153-649X, doi:10.5251/ajsir.2012.3.3.175.180

13. The suitability of partial replacement of cement with rice husk ash and bone powder in concrete structures, D. A. Opeyemi, O. O. Makinde, International Journal of Emerging Technology and Advanced Engineering Website: www.ijetae.com (ISSN 2250-2459, Volume 2, Issue 9, September 2012) 